\title{
SUGGESTIONS FOR NEW UNITS IN PHYSICS AND ENGINEERING
}

\begin{abstract}
A COMMUNICATION received from the Bureau International des Poids et Mesures summarizes the conclusions reached at the meetings last summer of the Consultative Committees for Electricity, Photometry and Thermometry. These conclusions would, in the normal course, have been reported to the International Committee for Weights and Measures at its meetings which were to have been held last September.

The Consultative Committee for Electricity recorded three resolutions. The first contains a recommendation as to the relationships which should be accepted between the existing international units and the proposed new practical absolute units, namely :

$$
\begin{array}{rlrl}
1 & \text { mean international ohm } & =1.0005 \mathrm{ohm} \text { (abs.) } \\
1 \quad, \quad, \quad \text { ampere } & =0.9999 \mathrm{amp} \text {. (abs.) } \\
1 \quad, \quad \text {, } & \text { volt } & =1.0004 \text { volt (abs.) }
\end{array}
$$

The second resolution contains a number of clauses defining the proposed new units and the procedure to be followed in establishing and maintaining suitable reference standards. The third relates simply to the desirability, in order to avoid confusion, of appending the qualification "international" (abbreviated to "int.") or "absolu" (abbreviated to "abs.") in all references to the two series of units during the period of transition.

The Consultative Committee for Photometry also passed three resolutions. The first of these suggested that, while the 'new candle' should be introduced in legislation as from January 1, 1940, its legal application should be deferred until January 1, 1941. The second records a recommendation that comparisons of lamps at the higher colour temperature of $2800^{\circ} \mathrm{K}$. should be organized forthwith between the various national laboratories; and the third outlines the relationship between the old and new units and the procedure to be adopted for the establishment of the new standards necessary.
\end{abstract}

The Consultative Committee for Thermometry passed two resolutions. The first of these records that, in the opinion of the Committee, the most probable value of the melting point of ice on the Kelvin scale, according to experiments so far completed, should be taken as $273 \cdot 15^{\circ} \pm 0 \cdot 02^{\circ}$. The second recommends that the unit of 'heat' should be the quantity of heat equivalent to the 'Joule', or $10^{7}$ ergs; that the calorie should be defined as $3600 / 860$ joules, or $1 / 860$ watt-hours ; and that the terms kilogram-calorie, or 'large' calorie, should in future be replaced by "kilo-calorie"; these recommendations to be submitted for approval, before final adoption, to the International Union of Physics, the Commission of Physico-Chemical Constants, and the Steam Tables Conference. In addition, the Committee recommended certain minor modifications to the existing specifications of the International Temperature Scale.

It will be realized that the functions of the Consultative Committees are purely advisory, and that any decisions based thereon must be taken by the International Committee itself. The fact that, as a result of the War, this Committee was unable to meet as arranged, has left all these various resolutions unconfirmed. In particular, some uncertainty arises as to the precise position with regard to the introduction of the proposed new electric and photometric units, which the International Committee had previously decided should come into force on January 1, 1940. The Consultative Committees concerned both encountered difficulty with regard to implementing these previous decisions.

In a covering letter to the summary, the acting president and secretary of the International Committee suggest that in all the circumstances, since uniformity of international action is most desirable in such matters, the introduction of the new units should be deferred until such time as the Committee is able to issue a further pronouncement.

\section{TYPE TESTS IN ENGINEERING}

$\mathrm{I}^{\mathrm{N}}$ a paper in the Beama Journal of January W. A. Coates, c/o Metropolitan-Vickers Electrical Co., Ltd., discusses the significance and value of type tests in engineering. A type test is defined as a text made on one piece of material or apparatus, which is accepted as indicating the characteristics of another. Naturally, therefore, there is always an element of chance when interpreting and applying the results of such tests.

One of the oldest examples of a type test is to be found in the practice of making castings with projecting portions, which are eventually cut or sawn off and tested for mechanical, physical or chemical characteristics or for two or three of them. It is probable that the data obtained in this way apply also to the casting; the latter, however, would be destroyed in similar tests. The value of tests on samples depends on the skill with which the pieces were located and if the metal were poured so as to ensure a uniform cooling rate with the main body of the casting. More trustworthy data are obtained by testing metal cut from the main body of the casting. In important parts this is often done by trepanning out a piece where a hole is required. The closer that such samples are taken from the metal which will be used, the nearer is the test to a true test.

In electrical work, analogous type tests can be found in Brit. Spec. 137 (1930), which deals with porcelain line insulators. In these tests for ascertaining the puncture and porosity figures, the insulator is destroyed in the process. The mechanical, electro-mechanical and temperature-cycle tests are 
carried out on a proportion only to save time and expense. Mechanical tests must, from their nature, be made on insulators one at a time, while temperature cycle tests cannot be made in less than six hours, and are very awkward to carry out with more than a few units at a time.

Skilled craftsmanship plays a greater part in porcelain manufacture, both in the moulding and the firing, than it does in the production of rolled or drawn metal. This is reflected in the incidence of tests. A simple set of tests would usually satisfy a purchaser of several tons of rolled steel, but of the insulators 0.5 per cent is the minimum standard quantity tested. If in these a failure is recorded, a second batch of 1 per cent is tested. A failure on the second group of tests is followed by tests on 1.5 per cent, and if there are defects among these, the whole quantity is rejected. The increasing size of the batch tested is a clear indication of increasing suspicion about the quality of the bulk. In more readily controlled materials it is not usual to increase the percentages tested, even if failure does occur in the initial batch.

Electrical work presents also another class of type-tests such as in those made to determine the impulse voltage characteristics of an insulator or bushing. The impulse ratio depends almost completely upon the physical dimensions and the relative dispositions of dielectrics and conductors in such apparatus. Without changing these features, there is practically nothing that can be done in course of manufacture which would sensibly alter the impulse breakdown values. Thus a type-test on any one of a batch of dimensionally similar units is adequate to prove the characteristics of all. It is, in fact, a purely design test.

The tests carried out by the Home Office Mines Departments at Buxton, to prove electrical apparatus safe for use in explosive atmospheres, are also in this group. Inspection which shows identity of detail conveys full confidence that duplicates of the tested apparatus are equally flameproof.

Recently, the industry has become increasingly aware of a new group of type-tests, namely, those made on circuit breakers, which are covered by certificates issued by the Association of Short-Circuit
Testing Authorities or the National Physical Laboratory. These two bodies are now working in conjunction to carry out and certify the short-circuit typetests made in conformity with the requirements of Brit. Spec. 116 (1937). This standard specification calls for other tests also, but these are of a well. understood nature and may be made with apparatus found in any properly equipped factory.

The over-voltage tests on insulation and those made to check the operation of tripping and closing coils, are carried out on every breaker as a matter of routine. Hydraulic tests to prove tank strength and adequacy of joints need not necessarily be made on every breaker. This also applies to the mechanical endurance test, which consists of opening and closing the breaker 500 times on no-load. A test of this kind is necessary on any complicated mechanism, to ensure that some trifle, which might cause ultimate failure by excessive wear or distortion in service, has not been overlooked "in design.

The practical circumstances in which a breaker may have to perform vary widely, and the accompanying electrical and physical phenomena are very complex. It is impossible, therefore, to separate the short-circuit tests into a series, each of which is simple and clearly defined, as can be done, for example, with an insulator. The only possible method of carrying out these tests is to use a testing generator which has short-circuit characteristics like those of the largest power stations. The operation, control, and recording work with such call for technical skill of an uncommon and very high order. The type-tests that have been devised are of an all-embracing character, and represent the worst that could happen in service; they are far more severe than is likely to occur in the majority of cases. It is essential to do this, because the primary duty of the breaker is to protect all other connected apparatus.

It will be generally agreed that the proper fields for type-testing are: (a) whenever the process of testing must destroy the article; $(b)$ whenever the test is to determine a characteristic which is dependent upon dimensions and physical positions of parts ; and $(c)$ whenever individual testing would increase the cost of the finished article to an uneconomic level.

\section{DUGGAN-CRONIN BANTU GALLERY, KIMBERLEY}

$\mathrm{W}$ HEN in 1929 the British Association visited South Africa, the anthropologists in particular were much impressed by the scientific value, as well as by the importance as a record, of the collection of photographs of characteristic types of the native races of South Africa, which had been formed and was still being augmented by $\mathrm{Mr}$. A. M. DugganCronin. This impression was fully confirmed by further examination of the material placed on exhibition by Mr. Duggan-Cronin at the centenary meeting of the Association held in London in 1931.

Mr. Duggan-Cronin's interest in native types was first aroused when, as an employee of the De Beers Company in Kimberley, he was brought into contact with the wide variety of tribesmen who sought employment in the mines. After mastering the technique, he began his photographic series of racial types in 1904 ; but it was not until 1919 that he was able to undertake work in the field, when at the instance of the Board of the MeGregor Institute, Kimberley, he visited the Langenbergen, Griqualand West, to photograph the Bushmen living there. Since that time, each year Mr. Duggan-Cronin, with the financial assistance of the Union Research Grant Board or from the Carnegie funds, has carried on his work, visiting one or other of the South African peoples, until a record has been made of every important Bantu tribe in the Union and of a number elsewhere, as well as of the Yellow races, Bushmen and Korannas. These records, to the number of 2,600 , have been mounted in albums and the negatives stored in a strong room of De Beers. The material has also been published in part in eight volumes with the Cambridge University Press, while seven further volumes await publication.

From 1925 onward Mr. Duggan-Cronin, in view 